\title{
Human Capital Development Strategy
}

\author{
Kostas Mavromaras \\ Future of Employment and Skills Research Centre \\ University of Adelaide \\ Adelaide, Australia \\ kostas.mavromaras@adelaide.edu.au
}

\author{
Christopher Findlay \\ University of Adelaide \\ Crawford School, Australian National University \\ Canberra, Australia \\ christopher.findlay@anu.edu.au
}

\begin{abstract}
The impact of technology compared to trade on events in labor markets, especially the changes in the wage premium (the ration of skilled to unskilled wages) and the mismatch of skills, is considered in this paper. The drivers and some outcomes are identified. New data from the Pacific Economic Cooperation Council is used to inform the discussion. The analysis leads to ideas about a new human capital development strategy relevant for globalised economies.
\end{abstract}

Keywords-Wage premium, skill mismatch, skill-biased technological change

\section{INTRODUCTION}

New problems emerge in labor markets due to changes in technology and globalization, relating to skills matching and human capital development. In this paper, we examine research on globalization and on technological change to identify some of the origins of these problems. We also identify the value of a new policy framework to help address them. In this way, we suggest the foundations for a human capital development strategy in the context of technological change and globalization.

In the next section, we review research results on the relative importance of trade and technology in driving changes in labor markets, focusing on the gainers and losers amongst the suppliers of labor. Our interest in doing so is to explain reported trends in the wage premium, defined here as the ratio of wages of skilled labor to those of unskilled labor. We examine in trends in developed and developing countries, compared to the expectations of trade theory. We also note the possible drivers of the outcomes in the movements of the wage premium, when the expectations are not met. In that respect we focus on the role of skilled biased technological change. Our interest is this part is the drivers of the 'price responses' in labor markets, that is, the changes in relative wages.

In the third part, we delve further into the nature of technological change, and the features that might cause it to be skilled-biased. We draw here on the results of a survey, which contained questions about the future of work, organized by the Pacific Economic Cooperation Council (PECC), as part of their annual report on The State of the Region [1]. We discuss how the impact of technological change might also be evident in the degrees of mismatch in skills in labor markets and in unemployment. Our interest here is in the quantity adjustments in labour markets.

In the fourth section, we review the policy challenges of the changes we identify. We conclude that these challenges are significant, and that the response will be complex. We note that a 'one size' human capital development strategy will not fit all but there are common elements across countries.

In our conclusion, we stress that while trade is not to 'blame' for all the developments in the labor market that we identify, it is already apparent that an attribution to trade has been made. Unless there is a response to that attribution then there will be significant challenges to economic integration and to capturing the benefits which it offers.

\section{WAGE INEQUALITY}

Consider the trends in the wage premium. Reference [2] reviews the data available from 1995 to 2009 on this ratio across developed and developing countries. The authors confirm the trend in developed (or OECD) countries of a rise in this ratio. They also find that on average the ratio has fallen in developing countries. But they point out that the average values hide substantial variations in the movements of the wage premium across countries. Some large developing countries show a rise in the ratio (for example, China, India and Mexico). Others, including Brazil, show a fall. Indonesia shows a lot of variation over time, initially falling, then from 1999 rising, and stabilizing from 2005.

These are both challenging and interesting outcomes. They are challenging since they indicate a general rise in inequality, at least among those who earn labor income. This is likely to generate a political response, because of the absolute change involved, and because of the change in relative wages and its consequences for perceptions of social standing. It is interesting since in the context of globalization it is not what we expect, as explained further below. In this part then we begin with a discussion of the likely drivers of this outcome, including those related to trade and those related to technology.

With respect to trade, we would expect globalization to increase overall welfare, but it will have significant redistributive effects. Along the lines of theory, wage inequality (among higher vs lower skilled labor) would be expected to rise in developed countries, given the abundance of skilled labor (which is expected to be used intensively in exports so their real wages rise relative to those of unskilled labor). It is expected to narrow in the developing countries that are abundant in unskilled labor and whose real wages would be expected to rise.

Generally, the literature indicates that this effect works in developed countries, so inequality increases between 
skilled and unskilled workers. This is the result we also reported above. Reference [3] finds that, in the US, median income has increased while inequality has also increased. But in developing countries there are instances of an increase in inequality, which is contrary to expectations ([4], [5]).

Drivers of this outcome in developing countries may include skill-biased technological change, which is for example embodied in imported capital goods. The productivity of all labor is augmented but the mix of employment shifts towards skilled labor as the new technology is adopted. Other factors may also be important explanators of the increase in inequality in developing countries, such as constraints on the ability of low-skilled labor to move to the locations of exportable production. But here we focus on the contribution of technological change.

Technological change accounts for nearly all (88\%) of loss of jobs in manufacturing in the US [3], so it appears that technology is more important than trade as a driver of changes in demand for different types of labor, which leads to changes in relative wages. An earlier study in the US [6] found that skilled-biased technological changes contributed to around $20 \%$ of wage inequality, but the share rose to around $50 \%$ in the 1980s and 1990s: the balance is attributed to trade.

Reference [7] finds that technological change explains about half of the change in the labor income share (another indicator of labor market outcomes) in advanced countries but that it has had no significant effect in emerging economies. In those economies, trade is more important, in the form of participation in global value chains. The explanation is that the jobs offshored in global value chains (GVCs) tend to be those where the ability to substitute capital for labor is relatively low. Where that substitutability is high, jobs will be retained in the home developed economies and new technology applied. However, the low degree of substitution means that developing economies find it difficult to use more laborintensive techniques in production, and so hosting GVC activities tends to lower the labor income share. Reference [8] makes the same point about GVC participation.

In summary, trade and technology contribute to labor market outcomes, including the shifts in the wage premium, both separately and jointly. Participation in trade, therefore, is important part of the set of drivers of redistribution, but not the whole, or even the main, story. Trade appears, however, to carry a share of blame in the commentary on these events, although perceptions differ between countries [5].

Why then does trade get 'blamed'? One observation is that 'you can't vote against the next generation of iPhones' [3]. It is also difficult to blame technology that can be so useful, and instead trade (and particularly trade agreements) became the scapegoat. Lack of appreciation of trade's contribution is another factor. For example, when a supply chain view is adopted, the so-called China shock in the US becomes a positive for employment, not a negative [9]: participating in a value chain adds to the competitiveness of the jobs that remain in the US, and which might otherwise be lost altogether. The issue is that the people in the jobs supported in this manner do not recognize this connection. Finally, unemployed people, who are usually a minority, are often blamed for their apparent inability to find a job (this is an example of a 'supply-side view' of the labor market).

Another reason why trade gets 'blamed' is that the evidence about the impact of technology on work is an emerging field that is not often well-documented. In the next section we attempt to provide more detail on technology and the changes in the nature of work.

\section{TeChNOLOGICAL CHANGE}

A distinction is sometimes made between enabling and replacing technologies. Enabling technologies help humans work more productively. For example, Computer Aided Design (CAD) software enables an architect to draw faster and more accurately. The service becomes cheaper and the savings are larger where hourly rate of saved wages is higher. Humans remain at the center of the scene, but some displacement due to CAD-like enabling technologies is possible and in some instances likely. Replacing technologies are designed to do away with humans in the work force. Humans are displaced by machines which undertake relatively routine tasks, although some jobs may be created in the management of the new technologies. These technologies, above all, destroy jobs. They create negative outcomes for some and a broad range of positive outcomes for others. They can reduce wages (for some), labor demand and overall employment. Almost always they will displace a group of workers. While their motivations differ, the main differences between these technologies is the relative size of the displacement effect. This is much larger in the case of replacing technologies. Both, however, we could also regard as 'skill-biased'.

The new technologies are highly international mobile. They are embodied in capital goods, which have also become significantly cheaper in relative terms [7]. Mobile human capital also carries this technology (for example, returning students), as do cross border transactions and foreign direct investment flows. It is not possible to be isolated from these trends.

The consequence in labor markets is that wages fall for the services of the types of labor displaced. However, while wages may adjust, the frictions involved in the process (such as search costs and the time taken to find new employment or to retrain) means that other outcomes will be observed, such as higher unemployment. These negative outcomes are intensified by the mismatch between the 'old' skills offered by the displaced workers and the 'new' skills required by the jobs created by the new technologies. This could be portrayed as an outward shift of the Beveridge curve, where a change in technology has resulted in more unemployment and more vacancies [10].

It is also useful to explore further how different sectors and occupations are affected and what skills are likely to be in demand, and to do so in the context of the way that labor markets work. This perspective provides a more informed foundation for a human capital strategy, which we will argue is not just a matter of building skills in the workforce.

There is little systematic data about the relationship between work, skills, occupations, qualifications and how all these may be influencing and be influenced by 
technological change in both advanced and emerging economies, especially in the Asia Pacific region. New data is available from the Pacific Economic Cooperation Council (PECC), which collected evidence through its annual survey and included an analysis of the future of work in its State of the Region 2018 - 2019 [1]. We use this data source to provide an empirical context to some of our core questions.

The PECC survey covered the whole of the Asia-Pacific policy community. The survey samples those whose views influence policy making in the region, falling into three main categories: Government; Business; Non-government: (Research community/civil society/media). The presentation is aggregated by sub-regions - Northeast Asia, North America; Oceania; Pacific South America; Southeast Asia. Percentages reported refer to the percentage of respondents $(n=529)$ with a specific response. Also, the survey asks for expectations of change by 2030, mostly in broad categories. Hence percentages of expectations for change should be interpreted accordingly: they are long-term perceptions by an influential but non-representative sample.

The expected impact of new technologies differs by sector. According to respondents, those likely to see an increase in employment were professional and scientific activities; arts entertainment and recreation; health and social work; information and communication; education; accommodation and food service. Likely to see a decrease were manufacturing; mining; agriculture; wholesale and retail trade; electricity and gas supply. Advanced and emerging economies respondents replied in a similar manner.

Measuring change by occupation is a useful metric. To the degree that occupations require specific qualifications and training, a focus on them offers an opportunity to design policy interventions. Among PECC survey respondents, there were also expectations of large differences in effects on various occupations. According to the net percentage of those who expect that employment will rise in an occupation minus those who expect it to fall, the following are the declining occupations.

- Clerical Support Workers

- Personal services and sales workers (shopping sales assistant, waiters)

- Handicraft and Printing Workers

- Food Processing, Woodworking, Garment and Other Craft and Related Trades Workers (butchers, tailors)

- Plant and Machine Operators and Assemblers (including train engine drivers, car and other transport drivers, trucks, mobile and fixed plant operators, ship deck crews)

- Cleaners and Helpers

- Laborers in Mining, Construction, Manufacturing and Transport

- Food Preparation Assistants \& Agricultural, Forestry and Fishery Laborers

- Street and Related Sales and Services Workers

Growing occupations include the following

- Science and Engineering Professionals

- Health Professionals (doctors, nurses, dentists)
- Information and Communications Technology Professionals

- Science and Engineering Associate Professionals

- Health Associate Professionals (eg medical and pharmaceutical technicians)

- Information and Communications Technicians

- Elderly care (Aged Care) workers

- Protective Services Workers (police, firemen, security guards)

Reference [7] also discusses the extent to which occupations are subject to technological change. Those most exposed are the jobs with are more easily routinised. These lists of declining and growing sectors, according to the PECC Survey respondents, appears to be aligned with that factor. The analysis of jobs at risk can be translated into sectors which are more exposed [7]. Accommodation and health services are less exposed while manufacturing and transportation is more exposed. These groups also match those of the PECC survey respondents.

The mismatch of skills has been reported to be high already in the Asian region, according to indicators such as employer responses to survey questions about difficulties in filling positions and rates of unemployment by education level [11]. The expectations of the PECC survey respondents of the extent of movement by occupation suggest that there is a significant risk of an even greater 'mismatch of skills' in the labor market. Labor will be released from employment, but their skills will not match those in demand. When this problem is significant, then the adjustment process will be slow, significant burdens will be borne by those displaced and there will be potential output which will be lost in the process [10]. Productivity and competitiveness are at risk when firms are forced to fill positions that require higher skills with low or unmatched skills in light of the shortage of qualified labor or leave the positions vacant. Similarly, a variety of research results (mostly from advanced economies) suggest that having workers who are overqualified in terms of academic credentials but lack the requisite specific competencies is a definite lose-lose proposition' ([11], p. 23).

In an environment of intense change, it is wise when designed responses to the skill mismatch problem to look at alternative and more generic definitions of skills (over and above those embedded in occupational classifications). Various studies have also grouped occupations according to common elements and examined trends in employment. For example, the OECD has examined changes in the nature of work in the US since 1960 [12]. They found that 'the share of non-routine analytic and interactive job tasks (tasks that involve expert thinking and complex communication skills) performed by American workers has increased steadily since 1960.

The share of routine cognitive and manual tasks began to decline in the early 1970 s and 1980s, respectively coinciding with the introduction of computers and computerised production processes. These are tasks that are more readily automated and put into formal algorithms. 
The share of non-routine manual tasks also declined, but stabilised in the 1990s, possibly due to the fact that they cannot be easily computerised or outsourced' [12] (p. 49)

If Asian economies follow these patterns of the US, then the extent of skills mismatch is likely to increase [11]. Historically, developing countries have had the option of taking over the production of goods from developed countries and applying more labor-intensive techniques. The observation has been made that doing so is becoming more difficult, for example because labor intensive methods fail to meet the production standards of GVCs.

With respect to generic skills, the PECC SOTR 2018-19 combined the top 10 lists of skills required to survive in the $4^{\text {th }}$ Industrial Revolution, from the World Economic Forum, namely the following:

- Critical thinking

- Complex problem solving

- Cognitive flexibility

- Judgement and decision making

- Creativity

- Emotional intelligence

- Active listening

- Negotiation

- People management

- Coordinating with others

- Quality control

- Service orientation

To a degree these skills are learnable but that doing so may take some time.

The PECC survey asked if there will be enough of the WEF-listed skills available to accommodate the expected demands from technological change? The list above ranks the skills in increasing level of difficulty. Beyond the top two, 10 percent or more of respondents thought it would be difficult to find these skills. The significance of these negative results is another indicator of the extent of the challenge of technological change. In the next sections, we elaborate on the policy challenges and responses.

\section{Policy Challenges}

Three sets of national institutions are important for managing change. These are education and training (to build the new skills for the new jobs and to handle the speed and depth of change and the different channels and methods of delivery, labor markets (the ability to match those available for work and the jobs open, the flexibility of operations) and social policy (including security and protection). The PECC Survey respondents were asked how prepared national institutions in their economies are to manage these issues. In emerging economies, the responses for 'not prepared' were 71 percent for the education system, 78 percent for the labor market and 79 percent for social policy (for advanced economy respondents these percentages were 62,74 and 72 respectively). Overall, this indicates a very high level of uncertainty about the ability to respond to the challenges evident in the perceptions of the impacts of technological change. Expectations on institutional readiness differed by type of respondent. Respondents were divided into business, government and non-government/academia and asked about their concerns for 12 elements of the responses: businesses are the most concerned (with respect to 8 out of 12 elements), nongovernment are in the middle (5/12) and government respondents report the least concern about institutional preparedness (1/12). Respondents were also divided into the sub-regions of North America, Northeast Asia, Oceania, Pacific South America and Southeast Asia: the most concerned are Pacific South America (12/12), North America (8/12), Southeast Asia (5/12), with a tie between Northeast Asia and Oceania (3/12)

Are we faced with a crisis? Perhaps crisis is too strong a word but the PECC survey respondents report their expectations of a significant shock. As digitalization and automation are changing so many economic and social parameters and doing so quickly, we cannot expect a smooth transition. We face uncertain outcomes of current new technologies and we continue to discover the unintended consequences of new technology. Even more uncertainty surrounds the outcomes and unintended consequences of technologies that have not been designed yet.

The goal will be to manage change, in order to adapt to these shocks and reveal a national opportunity for faster development supported by technology and to achieve results in a socially responsible manner, rewarding the "winners" and protecting the "left behinds". Changes in relative wages among different types of workers are inevitable, but we seek in addition to rewarding winners in that respect to also accommodate the losers, who suffer the costs of the processes of adjustment or whose incomes fall. Policy responses are discussed in the next section. world.

\section{POLICY RESPONSES}

The design of the response will be assisted in the first instance by quantifying likely changes, which will be hard to do given the timing and speed of these changes: data on events in labor markets (sectors, occupations, skill levels demonstrated by occupations, the extent of mismatch) however becomes very important. The next step is to translate the intelligence about events in labor markets into strategy for each of three core institutions: education and training, labor markets and social care. Here we speculate on the likely scope of new strategies for each of these institutions. The elaboration of these strategies is a topic for further work. In some cases, we suggest specific actions but otherwise we note the questions which might be considered in further research in order to refine these strategies.

For education and training, the response involves delivering new skills for digital jobs and building the capacity to handle change as a core skill of workers and employers. There is value in re-thinking school, technical and vocational education and training (TVET) and university to make education more connected to the demands from workplaces. The model of a single strong degree in the start of a working life (aiming at a long-lasting set of skills) may not be the best one anymore. Technology will keep changing the type of skills it demands. There is value in flexibility and making the education system more responsive to continual change and in teaching present and future workforces and workplaces how to connect and cope with change in the delivery of education itself. These could be the elements of a new national framework on education and skills. 
In addition to national investment, there is scope to use international cooperation to support the strategy linked to the development of education institutions. Economies in the region share these issues so there is also value in sharing experience in the design of the responses. There are gains from trade in education services all its modes, including foreign investment in the education sector. It adds capacity, but also it brings methods of education relevant to the building of skills which are important for the response to the challenges of technological change. Education is often poorly committed in trade agreements, so another important part of a national framework on education and skills is an open approach to trade and investment in this sector. Further research is valuable on the extent of commitments to openness in the education to date in various trade agreements and options for extending them.

The response for labor market institutions means applying more effort including the use of new technologies to find and support better ways of matching skills in demand and available. Demand for labor is changing and many "old" jobs and skills are lost while new jobs of the "old" type are not created. Workplaces will be expected to cope with change. Those released are apparently difficult to accommodate in new production systems: their employment cannot be organized in a way that substitutes for new technology while the employer remains competitive. What will the skills of the future be? How desirable is flexibility of work? What are the implications for the informal sector? Consideration of these issues will help build a new national "future of work" framework.

What is a crisis for some may be an opportunity for others: take the platform economy as one example. It presents challenges in many advanced economies, with formal and secure employment being converted into 'gig' work. In contrast the platform economy presents new opportunities for emerging economies, by providing pathways to reduce informal activity by increasing (social and economic) connectivity. The consequence is that the formal economy is helped to grow, by improving the position of youth and women. Thus, what may be a challenge for some advanced economies, can be an opportunity for emerging economies, by providing an avenue to modernize their rule-books via improved digital connectivity in many social and economic spheres (helping to integrate health, financial security and literacy, work, education and more).

For social policy, the response means working to respond to the presence of 'left behinds'. Job losses are expected but how many and when is not known. Part of (preventive) social care will focus on bearing the costs and organization of re-training and reintroducing displaced workers into the labor market. But there will inevitably be 'left behinds' and new problematic cohorts will emerge (older and less 'tech savvy' displaced workers and less welleducated youth who cannot find a job). What social care will be provided and by whom? What incentives to work will be built in the system? Changes in relative wages are likely to continue to occur and the wage premium may rise again: what policies applying to household incomes will respond to rising market inequality that follows? Consideration of these issues will help resolve the elements of a new national "social care" framework.
With respect to income policies, there are experiences in the region worth of study and comparison. In Australia for example, the Productivity Commission (PC) has estimated that the Gini coefficient has increased in market incomes over the last 27 years [13]. It finds however that the system of income taxes and transfers has reduced the Gini coefficient by 30 percent, while also noting the incentive effects of these measures for labor supply. The PC reports that households in Australia also receive in-kind transfers in health, education, housing and childcare, and when these are considered the Gini coefficient falls by another 30 percent. Institutions and policies for redistribution can have a significant impact on inequality, according to this experience which is worth further study.

\section{CONCLUSION}

We have reviewed the trends in inequality especially among the providers of labor services. We found that both trade and technological change contributed to these trends, both separately and jointly. We have also used data from the PECC to identify prospects for further changes in the demands for different types of labor. Our concern has been that the extent of the apparently already significant mismatches between jobs open and skills available may increase, leading to significant adjustment costs and loss of productivity.

We have proposed a broad structure for a response to these likely events, including a focus on three institutions education and training, labor markets and social care.

In practice, each of the three core national institutions is part of a policy chain. An integrated approach will allow fixing problems and weaknesses in a cost effective and balanced way. Our response will only be as strong as the weakest link of the policy chain. Our proposal is therefore to embrace the next industrial revolution with a new human capital development strategy, based on a set of frameworks linked to education and skills, work and social care.

The circumstances of economies vary significantly, including their exposure to the impacts of technological change and the timing of those effects as well as the current situation of the three core national institutions. As consequence while there are common elements of a new human capital development strategy, the weights on different activities are likely to vary across countries.

A final point is that the design of the human capital strategy is very important to sustain the momentum for economic integration and to continue to capture the benefits which it offers. Trade can carry more of the 'blame' we argue here for events in labor markets which have significant redistributive effects. There is risk of greater resistance to further integration, already apparent in higher income countries in Europe and in the US, in that case. This trend is less evident to date in Asia, but the risk remains. The consideration and management of a human capital development strategy is a critical part of the management of this risk.

\section{ACKNOWLEDGEMENTS}

The contents of this paper are informed by a project on the future of work, supported by the Pacific Economic Cooperation Council (PECC), Google, and the University of 
Adelaide. We thank Ed Pedrosa (PECC) and Tony Macri (Google) for their support and inspiration and many valuable conversations. Thanks go to the participants of the PECC annual conference (Singapore May 2018), the Philippines Institute of Development Studies (PIDS) Annual conference participants and staff of the Australian Department of Foreign Affairs and Trade (DFAT) (Manila Sept 2018) for their valuable comments. All errors and opinions are ours.

\section{REFERENCES}

[1] Pacific Economic Cooperation Council (PECC), State of the Region 2018 - 2019: Chapter 2 - The future of jobs and skills: https://www.pecc.org/state-of-the-region-reports/277-2018-2019/821chapter-2-the-future-of-jobs-and-skills

[2] Wang, W., S. Thangavelu and C. Findlay, 'Trade, Human Capital and Cross-border Production Linkages in Global Value Chains', working paper, Institute for International Trade, University of Adelaide, 2019.

[3] Noland, M., 'US trade policy in the Trump administration', Asian Economic Policy Review, 13(2), 2018, pp.262-278

[4] Ravallion, Martin, Inequality and globalization: A review essay', Journal of Economic Literature, 56, 2018, 620-42.

[5] Pavcnik, Nina (2017), 'The impact of trade on inequality in developing countries', Technical report, National Bureau of Economic Research.

[6] Blum, B.S., 'Trade, technology and the rise of the service sector: the effects on US wage inequality', Journal of International Economics, 74, 2008, 441-458.

[7] Dao, M.C., M. Das, Z. Koczan and W. Lian, 2017. 'Understanding the downward trend in labor income shares', Chapter 3 in IMF World Economic Outlook: Gaining Momentum, April, 2017, pp.121-172.

[8] Rodrik, D., 'New technologies, global value chains, and developing economies', Working Paper 25164, 2018, National Bureau of Economic Research.

[9] Wang, Z., S.J. Wei, X. Yu and K. Zhu, 'Re-examining the effects of trading with china on local labor markets: A supply chain perspective', Working Paper 24886, 2018, National Bureau of Economic Research.

[10] Mavromaras, K. and P. J. Sloane, 'Technology and Mismatch', Working Paper, 2019, Future of Employment and Skills Research Centre, University of Adelaide.

[11] Ra, S., B. Chin, and A. Liu, 'Challenges and opportunities for skills development in Asia: Changing supply, demand, and mismatches, 2015, Mandaluyong City, Philippines: Asian Development Bank.

[12] OECD, 'The Skills Needed for the 21st Century' in OECD Skills Outlook: First Results From the Survey of Adult Skills, 2015, OECD, Paris.

[13] Productivity Commission, 'Rising inequality? A stocktake of the evidence', Commission Research Paper, 2018, Canberra. 